\begin{tabular}{l}
\hline OPEN OA ACCESS Freely available online \\
http://www.banglajol.info/index.php/BJID/index \\
Correspondence \\
Bangladesh Journal of Infectious Diseases \\
April 2020, Volume 7, Number Suppl_1, Page S51-S53 \\
ISSN (Online) 2411-670X \\
ISSN (Print) 2411-4820 \\
DOI: https://doi.org/10.3329/bjid.v7i0.46803
\end{tabular}

\title{
Different Management Strategy of Covid19 Patients
}

\author{
Md. Ashraful Haque ${ }^{1}$, Lubana Akram² \\ ${ }^{1}$ Assistant Professor, Department of Blood Transfusion, Sheikh Hasina National Institute of Burn\& Plastic Surgery, Dhaka, \\ Bangladesh; ${ }^{2}$ Post Graduate Student [Paediatric Gastroenterology], Deputed to Bangabandhu Shiekh Mujib Medical University, \\ Dhaka, Bangladesh
}

[Received: 26 March 2020; Accepted: 2 April 2020; Published: 25 April 2020]

\section{TO THE EDITOR,}

Coronaviruses are important human and animal pathogens. At the end of 2019, a novel coronavirus was identified as the cause of a cluster of pneumonia cases in Wuhan, a city in the Hubei Province of China. It rapidly spread, resulting in an epidemic throughout China, followed by an increasing number of cases in other countries throughout the world. In February 2020, the World Health Organization designated the disease COVID-19, which stands for coronavirus disease 2019 ${ }^{1}$. The virus that causes COVID-19 is designated severe acute respiratory syndrome coronavirus 2 (SARS-CoV-2); previously, it was referred to as 2019-nCoV.

Full-genome sequencing and phylogenic analysis indicated that the coronavirus that causes COVID19 is a beta coronavirus in the same subgenus as the severe acute respiratory syndrome (SARS) virus (as well as several bat coronaviruses), but in a different clade. The structure of the receptor-binding gene region is very similar to that of the SARS coronavirus, and the virus has been shown to use the same receptor, the angiotensin-converting enzyme 2 (ACE2), for cell entry ${ }^{2}$. The Coronavirus Study Group of the International Committee on Taxonomy of Viruses has proposed that this virus be designated severe acute respiratory syndrome coronavirus 2 (SARS-CoV-2) ${ }^{3}$. The Middle East respiratory syndrome (MERS) virus, another beta coronavirus, appears more distantly related ${ }^{4-5}$. The closest RNA sequence similarity is to two bat coronaviruses, and it appears likely that bats are the primary source; whether COVID-19 virus is transmitted directly from bats or through some other mechanism like through an intermediate host is unknown ${ }^{6}$.

As it is very new in origin so there is no definite treatment protocol till date. Treatment depends according to manifestation and immunity status of the sufferers.

Incubation Period: The incubation period for COVID-19 is thought to be within 14 days following exposure, with most cases occurring approximately four to five days after exposure ${ }^{7}$.

Spectrum of Illness Severity: The spectrum of symptomatic infection ranges from mild to critical; most infections are not severe ${ }^{8-12}$.

- Mild with no or mild pneumonia

- Severe disease with dyspnea, hypoxia, or >50 percent lung involvement on imaging within 24 to 48 hours

- Critical disease with respiratory failure, shock, or multiorgan dysfunction

Risk factors for severe illness: Comorbidities that have been associated with severe illness and mortality include cardiovascular disease, diabetes mellitus, hypertension, chronic lung disease, cancer and chronic kidney disease. Particular laboratory features have also been associated with worse outcomes. These include lymphopenia, elevated liver enzymes, elevated lactate dehydrogenase (LDH), elevated inflammatory markers like Creactive protein (CRP), ferritin, elevated D-dimer $(>1 \mathrm{mcg} / \mathrm{mL}$ ), elevated prothrombin time (PT), 
elevated troponin, elevated creatinine phosphokinase (CPK) and acute kidney injury ${ }^{13-17}$.

\section{Clinical Manifestations}

Initial Presentation: Pneumonia appears to be the most frequent serious manifestation of infection, characterized primarily by fever, cough, dyspnea, and bilateral infiltrates on chest imaging. There are no specific clinical features that can yet reliably distinguish COVID-19 from other viral respiratory infections. The most common clinical features at the onset of illness were fever, fatigue, dry cough, anorexia, myalgia, dyspnea and sputum production. Less common symptoms have included headache, sore throat and rhinorrhea. In addition to respiratory symptoms, gastrointestinal symptoms like nausea and diarrhea have also been reported and in some patients, they may be the presenting complaint.

\section{Site of Care}

Home Care: Home management is appropriate for patients with mild infection who can be adequately isolated in the outpatient setting. Management of such patients should focus on prevention of transmission to others and monitoring for clinical deterioration, which should prompt hospitalization. Outpatients with COVID-19 should stay at home and try to separate themselves from other people and animals in the household. They should wear a facemask when in the same room (or vehicle) as other people and when presenting to health care settings. Disinfection of frequently touched surfaces is also important.

\section{Treatment: Symptomatic}

- Fever: Paracetamol $500 \mathrm{mg}$ according to body weight

- Nasal Discharge: Anti-Histamine

- Fluid intake as much as possible.

\section{When to Discontinue Home Isolation}

When a test-based strategy is used resolution of fever without the use of fever-reducing medications and improvement in respiratory symptoms like cough, shortness of breath and Negative results of molecular assay for COVID-19 from at least two consecutive nasopharyngeal swab specimens collected $\geq 24$ hours apart (total of two negative specimens).

When a non-test-based strategy is used at least seven days have passed since symptoms first appeared and at least three days (72 hours) have passed since recovery of symptoms which has been defined as resolution of fever without the use of fever-reducing medications and improvement in respiratory symptoms like cough, shortness of breath.

\section{Hospital Care}

\section{Severe Diseases}

- In adults with COVID-19, supplemental oxygen should be started by standard non-breather oxygen face mask. If the peripheral oxygen saturation (SPO2) is $<92 \%$.

- If acute hypoxemic respiratory failure persist despite conventional oxygen therapy, HFNC (High flow nasal oxygen cannula) should be used over conventional oxygen therapy.

- If HFNC not available, then trial of NIPPV with close monitoring and short-interval assessment for worsening of respiratory failure should be done.

- COVID-19 receiving NIPPV or HFNC, close monitoring should be ensuring for worsening of respiratory status, and early intubation in a controlled setting if worsening occurs.

\section{Critical Diseases}

- In adults with COVID-19 and shock, using dynamic parameters skin temperature, capillary refilling time, and/or serum lactate measurement over static parameters in order to assess fluid responsiveness.

- For the acute resuscitation of adults with COVID-19 and shock, conservative strategy should be followed over a liberal fluid strategy.

- First option should be crystalloids and target MAP (mean arterial pressure) will be 60 to $65 \mathrm{~mm}$ of $\mathrm{Hg}$ or more.

- If fluid not sufficiently improve pressure, then vasoactive agent can be used and first choice should be Norepinephrine.

- If Norepinephrine not available, then vasopressin or epinephrine.

- For adults with COVID-19 and shock with evidence of cardiac dysfunction and persistent hypoperfusion despite fluid resuscitation and norepinephrine, dobutamine should be added rather increasing norepinephrine dose.

- Routine use of corticosteroid should be avoided as it may increase viral replication.

- If ARDS established than $200 \mathrm{mg}$ corticosteroid can be given in divided dose over a day.

- If patient needs mechanical ventilation, then expert hand should attend to intubate as because failed intubation raises the chance of more contamination and video guided intubation is more preferable. 
- Full set of apparatus of mechanical ventilation should be used in each new patient.

\section{Drugs Therapy}

Lots of trial is going on but none of that is completed. Scientists have suggested dozens of existing compounds for testing, but WHO is focusing on what there are the four most promising therapies which are an experimental antiviral compound called remdesivir, the malaria medications chloroquine and hydroxychloroquine, a combination of two HIV drugs, lopinavir and ritonavir and that same combination plus interferonbeta, an immune system messenger that can help cripple viruses.

Convalescent Plasma therapy: On 24/03/2020 FDA has given small basis trial for giving plasma therapy collecting from recovered patient after proper procedure.

\section{Reference}

1. World Health Organization. Director-General's remarks at the media briefing on 2019-nCoV on 11 February 2020. https://www.who.int/dg/speeches/detail/who-director-generals-remarks-at-the-media-briefing-on-2019-ncov-on-11-february2020 (Accessed on February 12, 2020).

2.National Guidelines on Clinical Management of Corona virus Disease $2019 \quad$ (Covid-19) https://dghs.gov.bd/images/docs/Guideline/COVID_Guideline_ V4.30.3.2020.pdf

3.Zhou P, Yang XL, Wang XG, et al. A pneumonia outbreak associated with a new coronavirus of probable bat origin. Nature 2020; 579:270.

4.Gorbalenya AE, Baker SC, Baric RS, et al. Severe acute respiratory syndrome-related coronavirus: The species and its viruses - a statement of the Coronavirus Study Group. bioRxiv 2020.

https://www.biorxiv.org/content/10.1101/2020.02.07.937862v1 (Accessed on February 12, 2020).

5. Li Q, Guan X, Wu P, et al. Early Transmission Dynamics in Wuhan, China, of Novel Coronavirus-Infected Pneumonia. N Engl J Med 2020.

6. Guan WJ, Ni ZY, Hu Y, et al. Clinical Characteristics of Coronavirus Disease 2019 in China. N Engl J Med 2020.

7. Chan JF, Yuan S, Kok KH, et al. A familial cluster of pneumonia associated with the 2019 novel coronavirus indicating person-to-person transmission: a study of a family cluster. Lancet 2020; 395:514.
8. Lauer SA, Grantz KH, Bi Q, et al. The Incubation Period of Coronavirus Disease 2019 (COVID-19) From Publicly Reported Confirmed Cases: Estimation and Application. Ann Intern Med 2020

9. Bajema KL, Oster AM, McGovern OL, et al. Persons Evaluated for 2019 Novel Coronavirus - United States, January 2020. MMWR Morb Mortal Wkly Rep 2020; 69:166

10. Huang C, Wang Y, Li X, et al. Clinical features of patients infected with 2019 novel coronavirus in Wuhan, China. Lancet 2020; 395:497

11. Chen N, Zhou M, Dong X, et al. Epidemiological and clinical characteristics of 99 cases of 2019 novel coronavirus pneumonia in Wuhan, China: a descriptive study. Lancet 2020; 395:507

12. Wang D, Hu B, Hu C, et al. Clinical Characteristics of 138 Hospitalized Patients with 2019 Novel Coronavirus-Infected Pneumonia in Wuhan, China. JAMA 2020;323(11):1061-1069. doi:10.1001/jama.2020.1585

13. Liu K, Fang YY, Deng Y, et al. Clinical characteristics of novel coronavirus cases in tertiary hospitals in Hubei Province. Chin Med J (Engl) 2020

14. Yang X, Yu Y, Xu J, Shu H, Liu H, Wu Y, et al. Clinical course and outcomes of critically ill patients with SARS-CoV-2 pneumonia in Wuhan, China: a single-centered, retrospective, observational study. The Lancet Respiratory Medicine. 2020 Feb 24.

15. Grasselli G, Pesenti A, Cecconi M. Critical Care Utilization for the COVID-19 Outbreak in Lombardy, Italy: Early Experience and Forecast During an Emergency Response. JAMA. Published online March 13, 2020. doi:10.1001/jama.2020.4031

16. Onder G, Rezza G, Brusaferro S. Case-Fatality Rate and Characteristics of Patients Dying in Relation to COVID-19 in Italy. JAMA. Published online March 23, 2020. doi:10.1001/jama.2020.4683

17. Onder G, Rezza G, and Brusafero S. Case-Fatality Rate and Characteristics of Patients Dying in Relation to COVID-19 in Italy. JAMA 2020.

[Bangladesh Journal of Infectious Diseases, April 2020;7(suppl_1):S51-S53]

Correspondence: Dr. Md. Ashraful Haque, Assistant Professor, Sheikh Hasina National Institute of Burn \&Plastic Surgery, Dhaka, Bangladesh; Cell no.: +8801811173430; Email: ashraf.djmc03@gmail.com

Conflict of interest: All authors have no competing interests. How to cite this article: Haque MA, Akram L. Different Management Strategy of Covid19 Patients. Bangladesh J Infect Dis 2020;7(suppl_1):S51-S53

Copyright: @2020. Haque and Akram. Published by Bangladesh Journal of Infectious Diseases. This article is published under the Creative Commons CC BY-NC License (https://creativecommons.org/licenses/by-nc/4.0/). This license permits use, distribution and reproduction in any medium, provided the original work is properly cited, and is not used for commercial purposes. 